\title{
AKUPUNKTUR UND LASER GOES MAINSTREAM
}

\section{Liebe Kolleginnen und Kollegen,}

Akupunkturbehandlungen und Lasertherapien sind längst salonfähig und viele Studien erscheinen dazu in hochrangigen schulmedizinischen Journalen. Beispielsweise konnte nachgewiesen werden, dass Elektroakupunktur bei Frauen mit Stressinkontinenz wirksam sein kann. Die Studie dazu wurde vor kurzem im renommierten Journal JAMA $($ Impact Faktor $=44,4 !)$ von einem unserer Projektpartner
Studien zur Thematik liegen auch von Laserbehandlungen vor. In mittlerweile insgesamt 7 prospektiven, monozentrischen Studien lagen die Verbesserungsraten zwischen $62 \%$ und $78 \%$. (Prog. Urol. Oktober 2017). Es wurden keine schwerwiegenden unerwünschten Nebenwirkungen festgestellt. Um die relativen Vorteile und das Nebenwirkungsprofil der Laserbehandlung bei Stressinkontinenz im Vergleich zu anderen minimalinvasiven Verfahren zu bewerten, sind jedoch weitere Forschungsarbei-
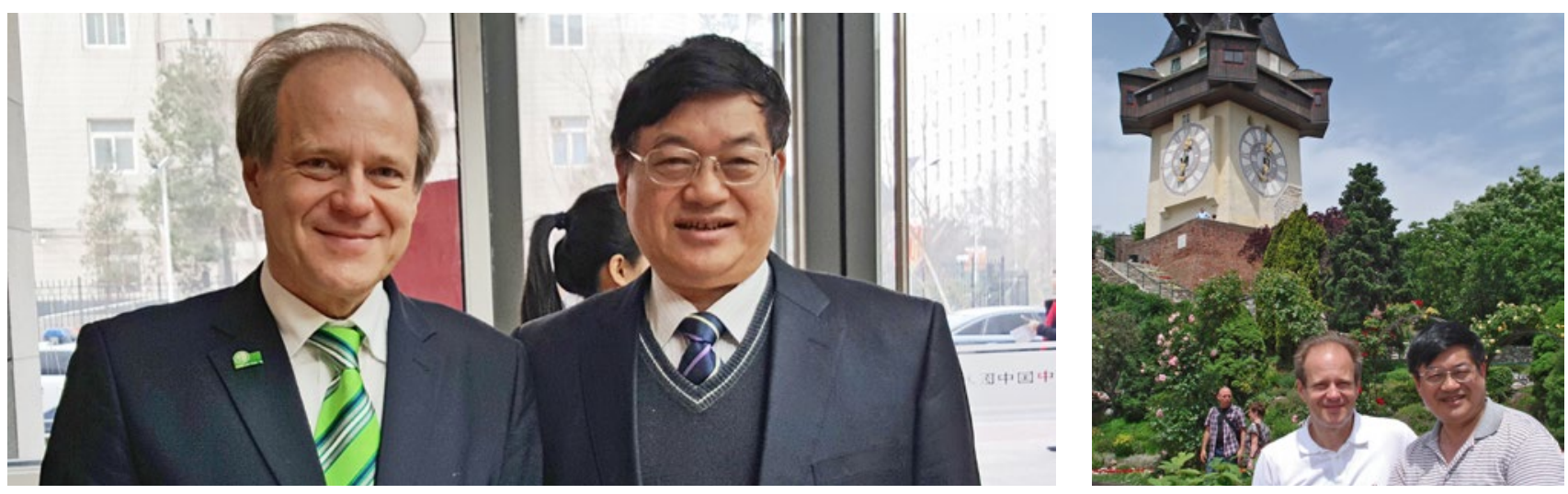

Abb. 1:Verantwortlicher Studienleiter Professor Baoyan Liu (China Academy of Chinese Medical Sciences) und Professor Gerhard Litscher in Peking und Graz

Professor Baoyan Liu (Abb. 1) publiziert (JAMA 2017; 317(24): 2493-2501). Es handelt sich dabei um eine multizentrische, randomisierte klinische Studie, die an 12 Krankenhäusern in China durchgeführt wurde. Die 504 Patientinnen wurden in 18 Sitzungen über 6 Wochen behandelt. Die Elektroakupunktur im lumbosakralen Bereich führte nach 6 Wochen zu weniger Harnverlust. ten erforderlich. Wünschen wir der Akupunktur, der Aurikulomedizin und der Lasertherapie weiterhin viele aussagekräftige wissenschaftliche Studien zum Wohle der Patientinnen und Patienten.

Mit freundlichen Grüßen und besten Wünschen für die bevorstehenden Feiertage

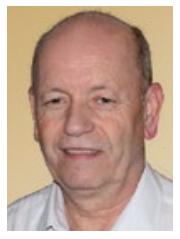

Dr. med. Dipl. Chem. Michael Weber

President for Medical and Clinical Applications der International Society for Medical Laser Applications (ISLAtranscontinental)

Klinik Neu-Mariahilf, Humboldtallee 10-12, D-37073 Göttingen, Tel. +49 5273/367 780

E-Mail:info@isla-laser.org,Internet:www.isla-laser.org

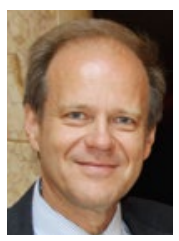

Univ.-Prof. Prof. h.c. DI Dr. techn.

Dr. scient. med. Gerhard Litscher

President for Science and Research der International Society for Medical Laser Applications (ISLAtranscontinental)

Medizinische Universität Graz, Auenbruggerplatz 29, A-8036 Graz, Tel: +43 316/385-13907, -83907

E-Mail:gerhard.litscher@medunigraz.at,Internet:http://litscher.info 